\title{
Nomograms predict survival outcome of Klatskin tumors patients
}

\author{
Feng Qi ${ }^{\text {Equal first author, 1 }}$, Bin Zhou ${ }^{\text {Equal first author, } 2}$, Jinglin Xia ${ }^{\text {Corresp. } 1}$ \\ ${ }^{1}$ Zhongshan Hospital, Fudan University, Shanghai, China \\ 2 Eastern Hepatobiliary Surgery Hospital, Shanghai, China \\ Corresponding Author: Jinglin Xia \\ Email address: gluckqi@163.com
}

Objective : Klatskin tumors are rare, malignant tumors of the biliary system with a poor prognosis for patient survival. The current understanding of these tumors is limited to a small number of case reports or case series, therefore, we examined prognostic factors of this disease.Methods:A population cohort study was conducted in patients selected from the Surveillance, Epidemiology, and End Results (SEER) database with a Klatskin tumor that was histologically diagnosed between 2004 to 2014. Propensity-matching (PSM) analysis was performed to determine the overall survival (OS) among those with a Klatskin tumor (KCC), intrahepatic cholangiocarcinoma (ICCA), or hepatocellular carcinoma (HCC). The nomogram was based on 317 eligible Klatskin tumor patients and its predictive accuracy and discriminatory ability were determined using the concordance index (Cindex).Results: Kaplan-Meier analysis showed that patients with Klatskin tumors had significantly worse overall survival rates (1-year OS $=26.2 \%, 2$-year OS $=10.7 \%$, 3-year OS $=3.4 \%$ ) than those with intrahepatic cholangiocarcinoma (1-year OS=62.2\%, 2-year OS $=36.4 \%$, 3-year OS $=19.1 \%, p<0.001)$ or hepatocellular carcinoma $(1$-year OS $=$ $72.4 \%, 2$-year OS $=48.5 \%, 3$-year OS $=36.2 \%, p<0.001$ ). A poor prognosis was also significantly associated with older age, higher grade, SEER historic stage, and lymph node metastasis. Local destruction of the tumor $(\mathrm{HR}=0.635,95 \% \mathrm{Cl} 0.421-0.956, \mathrm{p}=0.03)$ and surgery $(\mathrm{HR}=0.434,95 \% \mathrm{Cl} 0.328-0.574, \mathrm{p}<0.001)$ were independent protective factors. Multivariate Cox analysis showed that older age, SEER historic stage, and lymph node metastases $(\mathrm{HR}=1.468,95 \% \mathrm{Cl} 1.008-2.139, \mathrm{p}=0.046)$ were independent prognostic factors of poor survival rates in Klatskin tumor patients, while cancer-directed surgery was an independent protective factor $(\mathrm{HR}=0.555,95 \% \mathrm{Cl} 0.316-0.977, \mathrm{p}=0.041)$. The prognostic and protective factors were included in the nomogram (C-index for survival $=0.651 ; 95 \% \mathrm{Cl}$ 0.607-0.695Conclusions: The Klatskin tumor group had poorer rates of OS and cancer-specific survival than the ICCA and HCC groups. Early detection and diagnosis were associated with a higher rate of OS in Klatskin tumor patients. 


\section{Nomograms predict survival outcomes of Klatskin tumor patients}

2 Feng Qi $\mathrm{PhD}^{1 *}$, Bin Zhou $\mathrm{PhD}^{2 *}$, Jing-lin $\mathrm{Xia}^{1}$

$3 \quad{ }^{1}$ Liver Cancer Institute, Zhongshan Hospital, Fudan University, Shanghai, 200032, China;

$4 \quad{ }^{2}$ Department of Hepatic Surgery VI, Eastern Hepatobiliary Surgery Hospital, Second Military

5 Medical University, Shanghai, 200433, China.

$6 \quad *$ These authors contributed equally to this work

7 Correspondence: Jing-lin Xia, Professor

8 Liver Cancer Institute, Zhongshan Hospital, Fudan University, Shanghai, 200032, China. Tel, $9+862154237900$, Fax, +86 2154237621, E-mail xiajinglin@,fudan.edu.cn.

\section{Abstract}

11 Objective: Klatskin tumors are rare, malignant tumors of the biliary system with a poor

12 prognosis for patient survival. The current understanding of these tumors is limited to a small

13 number of case reports or case series, therefore, we examined prognostic factors of this disease. 
14

Methods: A population cohort study was conducted in patients selected from the Surveillance, Epidemiology, and End Results (SEER) database with a Klatskin tumor that was histologically diagnosed between 2004 to 2014. Propensity-matching (PSM) analysis was performed to determine the overall survival (OS) among those with a Klatskin tumor (KCC), intrahepatic cholangiocarcinoma (ICCA), or hepatocellular carcinoma (HCC). The nomogram was based on 317 eligible Klatskin tumor patients and its predictive accuracy and discriminatory ability were determined using the concordance index (C-index).

Results: Kaplan-Meier analysis showed that patients with Klatskin tumors had significantly worse overall survival rates $(1$-year OS $=26.2 \%, 2$-year OS $=10.7 \%, 3$-year OS $=3.4 \%)$ than those with intrahepatic cholangiocarcinoma $(1$-year OS=62.2\%, 2-year OS $=36.4 \%, 3$-year OS $=$ $19.1 \%, \mathrm{p}<0.001)$ or hepatocellular carcinoma $(1$-year OS $=72.4 \%, 2$-year OS $=48.5 \%$, 3-year $\mathrm{OS}=36.2 \%, \mathrm{p}<0.001)$. A poor prognosis was also significantly associated with older age, higher grade, SEER historic stage, and lymph node metastasis. Local destruction of the tumor $(\mathrm{HR}=0.635,95 \% \mathrm{CI} 0.421-0.956, \mathrm{p}=0.03)$ and surgery $(\mathrm{HR}=0.434,95 \% \mathrm{CI} 0.328-0.574$, $\mathrm{p}<0.001)$ were independent protective factors. Multivariate Cox analysis showed that older age, SEER historic stage, and lymph node metastases $(\mathrm{HR}=1.468,95 \%$ CI $1.008-2.139, \mathrm{p}=0.046)$ were independent prognostic factors of poor survival rates in Klatskin tumor patients, while cancer-directed surgery was an independent protective factor $(\mathrm{HR}=0.555,95 \%$ CI $0.316-0.977$, $\mathrm{p}=0.041)$. The prognostic and protective factors were included in the nomogram $(\mathrm{C}$-index for survival $=0.651 ; 95 \%$ CI $0.607-0.695$

Conclusions: The Klatskin tumor group had poorer rates of OS and cancer-specific survival than the ICCA and HCC groups. Early detection and diagnosis were associated with a higher rate of OS in Klatskin tumor patients. 
38 Introduction

39 Cholangiocarcinoma (CCA) is a heterogeneous, malignant tumor with an extremely poor prognosis for survival. It is the second most common primary hepatic malignancy and makes up 3\% of all gastrointestinal tumors. ${ }^{1}$ Studies conducted in North America, Europe, Asia, and Australia have shown a steady increase in the incidence of CCA over the past few decades. ${ }^{2}$ The cause of this increase is unclear but may be attributed to several risk factors, including primary sclerosing cholangitis, ulcerative colitis, cirrhosis, hepatitis B, infection by certain liver flukes, and some congenital liver malformations. ${ }^{3} \mathrm{CCA}$ is thought to develop in a histologically similar manner to colon cancer, with a series of stages from early hyperplasia and metaplasia to dysplasia and, ultimately, to the development of cancer. ${ }^{4}$ Cholangiocarcinoma can develop in any area of the bile duct, including in the bile ducts within the liver (intrahepatic), outside of the liver (extrahepatic), and in the perihilar region. ${ }^{5}$

In 1965, Klatskin identified 13 cases of adenocarcinoma in the hepatic duct bifurcation and named this tumor type the Klatskin tumor, or hilar cholangiocarcinoma (HCCA). ${ }^{6}$ Klatskin tumors were then further divided into two types due to their poor definition in the extrahepatic and intrahepatic bile ducts, known as extrahepatic hilar cholangiocarcinoma (EHC) and intrahepatic hilar cholangiocarcinoma $(\mathrm{IHC})^{6}$, respectively; they have similar histological characteristics based on the International Classification of Disease-Oncology (ICD-O) and T. Ebata's report. ${ }^{7}$ Previous studies have primarily focused on case reports or series based on the anatomical location of this disease while cohort studies performed have only examined the annual incidence and treatment of this disease. ${ }^{8}$ The prognostic factors of Klatskin tumors have not yet been compared with those of ICCA and HCC. 
60

61

62

64

65

66

67

68

69

We retroactively analyzed data taken from the Surveillance, Epidemiology, and End Results (SEER) database for patients diagnosed with a Klatskin tumor or ICCA. HCC was used as a point of reference to compare the clinical features, prognostic factors, and overall survival (OS) between Klatskin tumor and ICCA patients in order to further explore the factors that influence OS.

\section{Material and methods}

\section{Patient data}

Stat version 8.2.1 of SEER was used to download data from all patients with a diagnosis of liver cancer and cholangiocarcinoma from 2005 to 2015, according to the ICD-0-3/WHO 2008 guidelines. The main inclusion criteria were as follows: age 0 to 104 years, liver cancer with cholangiocarcinoma as the main malignant cancer diagnosis, pathological types of Klatskin tumors (based on ICD-O-3 8162/3), ICCA (based on ICD-O-3 8160/3), and HCC (based on ICDO-3 8170/3). We also examined the gender, ethnicity, lymph node metastases, histological grades I to IV, definite AJCC TNM stages, and type of therapeutic strategy. We excluded patients with an unclear T stage record, and unknown survival time, diagnostic confirmation, or surgery strategy. Patients were included based on a diagnosis of liver cancer and cholangiocarcinoma before 2014 to ensure sufficient time for follow-up (Figure 1). The study was in compliance with the ethics statement of Zhongshan Hospital, Fudan University.

\section{Statistical analysis}

Normalized continuous variables with a homogeneity of variance were compared using the $t$ test; the Mann-Whitney U test was performed for all other variable calculations. Multiple groups were compared using ANOVA and Tukey's post hoc test. The chi-square test was applied to the 
82 categorical data. Patients were divided into three groups according to pathology: Klatskin tumor

83 group, the ICCA group, and the HCC group. The demographic and clinical characteristics of the

84 three groups were compared using the chi-square test. Continuous variables were presented as

85 mean $\pm \mathrm{SE}$ or median (minimum, maximum), and the categorical variables were calculated as a

86 percentage. PSM analyses were performed based upon age, race, gender, grade, historic stage,

87 AJCC $6^{\text {th }}$ stage, tumor size, lymph node status, surgical method, alpha-fetoprotein (AFP) level,

88 and fibrosis score at a 1:1 ratio to adjust for the differences among the Klatskin tumor, ICCA,

89 and HCC groups. The Kaplan-Meier method was used to plot the survival curve. The unadjusted

90 OS rate of the different histological subtypes was adjusted using the log-rank test. OS was

91 defined from the date of diagnosis to the date of death or final follow-up. Cox proportional

92 hazard regression models were used to evaluate prognostic factors and HR was used as the 95\%

93 confidence interval. Diagnostic age, summary stage, lymph node metastases, and the treatment of

94 the primary tumor were included in the survival analysis. The above statistical data were

95 analyzed using the SPSS version 22.0 software package (IBM SPSS Statistics, Chicago, IL, US)

96 and $\mathrm{p}<0.05$ was considered statistically significant.

\section{Results}

Demographic, tumor, and treatment characteristics of patients with Klatskin tumors, ICCA, or

HCC

A total of 65,450 patients met the inclusion criteria for our study, including 317 Klatskin tumor patients, 7,316 ICCA patients, and 57,817 HCC patients. The demographic and clinical characteristics of all patients are summarized in Table 1. The composition of the three groups differed significantly by age, race, gender, degree of differentiation, AJCC stage, surgical 
104 method, alpha fetoprotein (AFP), and fibrosis score. Klatskin tumors occurred more frequently in

105 older patients $(72.78 \pm 13.29,66.76 \pm 12.99$ vs $63.62 \pm 11.48, \mathrm{p}<0.001)$ and among white men,

106 which is similar to the demographics of the ICCA and HCC groups $(79.5 \%, 78.3 \%$ vs $68.3 \%$,

$107 \mathrm{p}<0.001)$. The localized and regional historic stages for patients with Klatskin tumors was $31.2 \%$

108 and $31.9 \%, 26.8 \%$ and $30.2 \%$ for the ICCA group, and $49.7 \%$ and $27.9 \%$ for the HCC group,

109 respectively $(\mathrm{p}<0.001)$. We lacked sufficient data to generate statistically significant results when

110 running comparison analyses of the treatment method. The overall incidence rate of Klatskin

111 tumors decreased between 2004 and $2014(\mathrm{r}=-0.94, \mathrm{p}<0.001)$ while the rates of ICCA $(\mathrm{r}=0.89$,

$112 \mathrm{p}<0.001)$ and $\mathrm{HCC}(\mathrm{r}=0.73, \mathrm{p}=0.011)$ increased (Figure 2).

\section{Survival and prognostic factors for Klatskin tumor, ICCA, and HCC patients}

Kaplan-Meier analysis was used to evaluate OS and cancer-specific survival (Figure 2).

Klatskin tumor patients had worse survival rates than ICCA and HCC patients (median OS: 5 months vs 9 months and 14 months, $\mathrm{p}<0.001$; median cancer-specific survival: 10 months vs 13 months and 23 months, $\mathrm{p}<0.001$ ). The 1-, 2- and 3-year OS rates of Klatskin tumor, ICCA, and HCC patients were $26.2 \%$ versus $62.2 \%$ and $72.4 \%, 10.7 \%$ versus $36.4 \%$ and $48.5 \%$, and $3.4 \%$ versus $19.1 \%$ and $36.2 \%$, respectively. The X-tile program was used to divide all patients into two groups according to age in order to more accurately determine the prognosis. Further stratification studies showed that age at diagnosis, race, gender, tumor differentiation, SEER historic stage, tumor size, lymph node status, surgical intervention (including local tumor destruction and surgery), AFP level, and fibrosis score had a significant impact on the OS of Klatskin tumor, ICCA, and HCC patients $(\mathrm{p}<0.05)$ (Figure 3$)$.

The results of the Kaplan-Meier analysis of OS were further analyzed using univariate and multivariate Cox regression models. According to the univariate factor analysis, older age, worse 
127 pathological grade, larger tumor size, lymph node metastases, lower AFP level, and late TNM 128 and SEER stages were significantly related to a worse prognosis $(\mathrm{p}<0.05)$ (Table 2$)$. In contrast, 129 surgical intervention and histologic type were low risk factors $(\mathrm{p}<0.001)$. Adjusting the variables 130 did not impact the results of the multivariate analysis, except in regard to lymph node metastases $131(\mathrm{p}=0.089)$.

132 PSM analysis was performed to adjust for the unmatching cohort and a total of 317 Klatskin tumor patients were matched with 317 ICCA and 317 HCC patients (1:1:1) (Table 3$)$. In the matching cohorts, the Klatskin tumor group had worse 1-, 2-, 3-year OS rates than the ICCA and HCC groups (1-year OS: $28.4 \%$ versus $71.9 \%$ and $85.6 \%$; 2 -year OS: $13.3 \%$ versus $52.5 \%$ and 73.0\%; 3-year OS: $5.2 \%$ versus $38.1 \%$ and $66.1 \%$ ). The median OS in the Klatskin tumor group was 5 months compared with 26 and 68 months in the ICCA and HCC groups, respectively. The median cancer-specific survival in the Klatskin tumor group was 10 months compared with 34 months in the ICCA group $(\mathrm{p}<0.001)$ (Figure 4). Kaplan-Meier analysis and univariate Cox regression was used for further stratification studies and the results were similar to those of the un-matched cohorts (Figure 5). Based on multivariable analysis, the prognostic factors for OS were older age (HR 1.736, 95\% CI 1.396-2.157, p<0.001), lymph node metastasis (HR 1.406, 95\% CI 1.093-1.808, p=0.008), surgical intervention, lower AFP level (HR 0.757, 95\% CI 0.587-0.976, $\mathrm{p}=0.032)$ and histologic type (Table 4).

\section{Klatskin tumor patient survival and prognostic factors}

317 patients were identified with Klatskin tumors from 2004 to 2014 and a Kaplan-Meier analysis was performed based on patient characteristics (Table 1). Kaplan-Meier survival curves and log-rank analysis showed that a poorer prognosis was associated with older age (median OS: 3 months versus 7 months, $\mathrm{p}<0.001$ ), distant stage (median OS: localized 7 months, regional 6 
150 months versus distant 2 months, $\mathrm{p}<0.001$ ), no surgery (median OS: 5 months vs 17 months,

$151 \mathrm{p}<0.001$ ), and lymph node metastases (median OS: 3 months vs 7 months, $\mathrm{p}=0.016$ ) (Figure 6).

152 Multivariate Cox analysis of the 317 Klatskin tumor patients showed that older age (HR

153 1.725, 95\% CI 1.324-2.249, $\mathrm{p}<0.001$ ), late SEER historic stage (HR 3.594, 95\% CI 1.251-

154 10.326, $\mathrm{p}=0.018)$, and lymph node metastases $(\mathrm{HR}=1.468,95 \%$ CI 1.008-2.139, $\mathrm{p}=0.046)$ were

155 independent prognostic factors for worse survival. Conversely, cancer-directed surgery was an

156 independent protective factor that decreased the risk of death by $44.5 \%$ for Klatskin tumor

157 patients $(\mathrm{HR}=0.555,95 \%$ CI $0.316-0.977, \mathrm{p}=0.041)$ (Table 5).

158

159

160

161

162

163

164

165

166

167

168

169

170

171

\section{Prognostic nomogram for Klatskin tumor}

The prognostic nomogram was used to integrate all of the significant independent factors for OS in the Klatskin tumor group (Figure 7). The patients were divided into three groups according to age using the X-tile program. The optimal cut-off points were at 71 and 82 years of age. A prognostic nomogram was established to more accurately determine the survival of Klatskin tumor patients using all of the significant independent variables based on multivariate Cox analysis (Figure 7A). The C-index for OS prediction was 0.651 (95\% CI 0.607-0.695). The calibration plot for the probability of survival at 1,2, and 3 years showed an optimal agreement between the prediction by nomogram and actual observation (Figure 7B and 7C). The ROC curve was used to predict the accuracy of the model and the analysis was in agreement with the nomogram with a value of 0.884 in the area under the curve (AUC) $(p<0.001$, Figure 7D).

\section{Discussion}

Klatskin tumors are rare but their incidence has been on the rise since their identification in 1965. ${ }^{6}$ However, the clinicopathological features and outcomes of this disease remain unclear. In 
172 our study, we evaluated the clinicopathological features and prognostic factors of Klatskin

173 tumors using data from the SEER database from 2004 to 2014. We found the prevalence of

174 Klatskin tumors from this database to be very low when compared with

175 intrahepatic cholangiocarcinoma (ICCA) (317 versus 7,316 cases, respectively).

176 The mean age at diagnosis was 73 , which is consistent with the report by Sharmaa et al. ${ }^{8}$.

177 White patients were predominant in this cohort (75.0\%), which was expected given the overall 178 racial distribution of the Western population. Of the 317 cases, more males were affected than 179 females, but this difference was small (176:141). Most Klatskin tumor patients did not undergo 180 surgery or local destruction of the tumor. Patients with regional and localized tumors in the early 181 stages of the disease accounted for $63.1 \%$ of the Klatskin tumor cohort.

182 Klatskin tumors were found to have a worse prognosis than ICCA or hepatocellular 183 carcinoma and were more clinically aggressive with a worse prognosis than HCC. The median 184 OS for patients with CCA of the pancreas was nearly half that of patients with HCC. ${ }^{9,10}$ The 185 prognosis of Klatskin tumors was closely related to age, lymph node status, summary stage, and 186 local treatment of the primary tumor according to multivariate regression analysis. Overall 187 survival (OS) was influenced by summary stage, lymph node metastases, and surgery. consistent definitions and disease progression measures that clearly demonstrate the poor prognosis of Klatskin tumor patients. ${ }^{11}$ Among the 317 Klatskin tumor patients, 103 were not categorized by AJCC stage. Thus, we adjusted the SEER historic stage based on other variables and included these data in the multivariate Cox analysis. The results showed that the SEER historic stage is likely associated with poor prognosis. Klatskin tumors have different etiologies 
195 and biological features than ICCA and HCC but the treatment is similar. ${ }^{12,13}$ Previous studies

196 have shown a correlation between radical surgical excision and tumor characteristics and

197 stage. ${ }^{14,15}$ Juntermanns et al. ${ }^{16}$ reported an improved long-term survival rate after the tumor and

198 caudate lobe were completely resected. The results of our study were consistent with previous

199 reports that patients who underwent surgery had much better rates of survival than those who did

200 not. The local destruction of tumors was performed more frequently in HCC patients and was a

201 confounding factor that impacted the difference in prognosis between the HCC and Klatskin

202 tumor groups. This confounding factor caused a shorter OS in Klatskin tumor patients. Patients

203 were more likely to be treated with surgery when the cancer was regional and localized and when

204 the disease was at an early TNM stage. Molina et al. ${ }^{17}$ also reported high mortality rates in

205 Klaskin tumor patients related to vascular metastases and lymph node involvement. Lymph node

206 metastases were an independent prognostic protective factor for Klatskin tumor patients in our

207 cohort. The median OS of Klatskin tumor patients with no lymph node metastases was relatively

208 longer (7 months). Nomograms are thought to be more accurate than the conventional staging

209 systems for predicting prognosis in some cancers ${ }^{18,19}$. We constructed a prognostic nomogram,

210 which performed well in predicting survival in Klatskin tumor patients as indicated by the C-

211 index (0.651) and the calibration curve.

212 There are several hypotheses regarding the etiology of Klatskin tumors although its origins

213 are still unknown. The most likely causes are primary sclerosing cholangitis, ulcerative

214 colitis, cirrhosis, hepatitis B, infection with certain liver flukes, and certain congenital liver

215 malformations $^{3}$; genetic abnormalities and molecular defects in various oncogenes may also play

216 a role. $^{6}$ 
217 The SEER database provided the population of patients for our research. However, there 218 were limitations to our study. Serum CA19-9 expression is not widely used as a tumor marker in 219 the SEER database ${ }^{20}$ so we were not able to adjust for CA19-9 expression in the multivariate 220 Cox analysis. Alpha fetoprotein (AFP) and hepatic fibrosis score status could only be separated 221 into a single stratified study for prognosis. Due to the smaller sample size of only 317 Klatskin 222 tumor patients enrolled, we were not able to fully calculate the mode. Differing treatments for 223 liver cancer and cholangiocarcinoma also affected the prognosis. Additionally, the SEER 224 database contains no data regarding chemotherapy, interventional therapy, or targeted therapy. 225 In conclusion, our study compared the clinical features of Klatskin tumors, ICCA, and HCC using Kaplan-Meier analysis and multivariate Cox analysis. We confirmed that the prognosis of

227 Klatskin tumors was worse than that for ICCA or HCC. Age, lymph node status, summary stage, 228 and the local treatment of the primary tumor were prognostic factors. Our nomogram objectively 229 and accurately predicted the prognosis of Klatskin tumor patients.

\section{Acknowledgments}

231 We thank PeerJ for its linguistic assistance during the preparation of this manuscript. 
232

233

234

235

236

237

238

239

240

241

242

243

244

245

246

247

248

249

250

251

252

253

254

\section{References}

1. Blechacz \& Gores (2008) Blechacz BR, Gores GJ. Cholangiocarcinoma. Clin Liver Dis. 2008;12(1):131-150, ix.

2. Patel (2001) Patel T. Increasing incidence and mortality of primary intrahepatic cholangiocarcinoma in the United States. Hepatology. 2001;33(6):1353-1357.

3. Razumilava \& Gores (2014) Razumilava N, Gores GJ. Cholangiocarcinoma. The Lancet. 2014;383(9935):2168-2179.

4. Sirica (2005) Sirica AE. Cholangiocarcinoma: molecular targeting strategies for chemoprevention and therapy. Hepatology. 2005;41(1):5-15.

5. DeOliveira et al. (2007) DeOliveira ML, Cunningham SC, Cameron JL, et al. Cholangiocarcinoma: thirty-one-year experience with 564 patients at a single institution. Ann Surg. 2007;245(5):755-762.

6. Okuda et al. (1977) Okuda K, Kubo Y, Okazaki N, Arishima T, Hashimoto M. Clinical aspects of intrahepatic bile duct carcinoma including hilar carcinoma: a study of 57 autopsy-proven cases. Cancer. 1977;39(1):232-246.

7. Ebata et al. (2009) Ebata T, Kamiya J, Nishio H, Nagasaka T, Nimura Y, Nagino M. The concept of perihilar cholangiocarcinoma is valid. Br J Surg. 2009;96(8):926-934.

8. Sharma \& Yadav (2018) Sharma P, Yadav S. Demographics, tumor characteristics, treatment, and survival of patients with Klatskin tumors. Ann Gastroenterol. 2018;31(2):231-236.

9. Bridgewater et al. (2014) Bridgewater J, Galle PR, Khan SA, et al. Guidelines for the diagnosis and management of intrahepatic cholangiocarcinoma. J Hepatol. 2014;60(6):1268-1289. 
10. Sapisochin et al. (2014) Sapisochin G, de Lope CR, Gastaca M, et al. Intrahepatic cholangiocarcinoma or mixed hepatocellular-cholangiocarcinoma in patients undergoing liver transplantation: a Spanish matched cohort multicenter study. Ann Surg. 2014;259(5):944-952.

11. Edge \& Compton (2010) Edge SB, Compton CC. The american joint committee on cancer: the 7th edition of the AJCC cancer staging manual and the future of TNM. Ann Surg Oncol. 2010;17(6):1471-1474.

12. Deoliveira et al. (2011) Deoliveira ML, Schulick RD, Nimura Y, et al. New staging system and a registry for perihilar cholangiocarcinoma. Hepatology. 2011;53(4):13631371.

13. Mansour et al. (2015) Mansour JC, Aloia TA, Crane CH, Heimbach JK, Nagino M, Vauthey JN. Hilar cholangiocarcinoma: expert consensus statement. HPB (Oxford). 2015;17(8):691-699.

14. Scurtu et al. (2017) Scurtu RR, Dindelegan G, Bintintan V, Drasovean R, Apostu R, Ciuce C. Extension of hepatic resection ameliorates survival in patients with type IIIa or IIIb Klatskin tumors despite surgical complications. Chirurgia (Bucur). 2017;112(3):301-307.

15. Ito et al. (2009) Ito F, Cho CS, Rikkers LF, Weber SM. Hilar cholangiocarcinoma: current management. Ann Surg. 2009;250(2):210-218.

16. Juntermanns et al. (2016) Juntermanns B, Fingas CD, Sotiropoulos GC, et al. Klatskin tumor: long-term survival following surgery. Chirurg. 2016;87(6):514-519.

17. Molina et al. (2015) Molina V, Sampson J, Ferrer J, et al. Klatskin tumor: diagnosis, preoperative evaluation and surgical considerations. Cir Esp. 2015;93(9):552-560. 
285

286

287

288

289

290

291

292

293

294

295

296

297

298

299

300

18. Touijer \& Scardino (2009) Touijer K, Scardino PT. Nomograms for staging, prognosis, and predicting treatment outcomes. Cancer. 2009; 115:3107-11.

19. Wang et al. (2013) Wang Y, Li J, Xia Y, et al. Prognostic Nomogram for Intrahepatic Cholangiocarcinoma After Partial Hepatectomy. J Clin Oncol. 2013; 31(9):1188-95.

20. Patel et al. (2000) Patel AH, Harnois DM, Klee GG, LaRusso NF, Gores GJ. The utility of CA 19-9 in the diagnoses of cholangiocarcinoma in patients without primary sclerosing cholangitis. Am J Gastroenterol. 2000;95(1):204-207.

\section{Figures legends}

Figure 1 Flowchart of the enrolled patients in the study according to inclusion and exclusion criterion.

Figure 2 Kaplan-Meier curve of overall survival and the incidence trend: Overall survival (A) and cancer specific survival (B) according to histologic type of Klatskin tumors, ICCA or HCC before propensity score matching. The incidence trend for Klatskin tumor (C), ICCA (D) and $\mathrm{HCC}(\mathrm{E})$.

\section{Figure 3 Kaplan-Meier curve of overall survival in Klatskin tumor, ICCA and HCC}

patients before propensity score matching stratified by (A) age at diagnosis; (B) race; (C) gender; (D) primary tumor differential grade; (E) SEER historic stage; (F) AJCC stage; (G) primary tumor size; (H) lymph node status; (I) surgery for primary tumor; (J) AFP level; (K) fibrosis score.

Figure 4 Kaplan-Meier plot and log-rank test: Overall survival (A) and cancer specific survival (B) according to histologic type of Klatskin tumors, ICCA or HCC after propensity score matching. 
301

302

303

304

305

306

307

308

309

310

311

312

313

314

315

316

Figure 5 Kaplan-Meier curve of overall survival in Klatskin tumor, ICCA and HCC

patients after propensity score matching stratified by (A) age at diagnosis; (B) race; (C) gender;

(D) primary tumor differential grade; (E) SEER historic stage; (F) AJCC stage; (G) primary

tumor size; (H) lymph node status; (I) surgery for primary tumor; (J) AFP level; (K) fibrosis score.

Figure 6 Kaplan-Meier curve of overall survival in Klatskin tumor patients stratified by
(A) age at diagnosis; (B) race; (C) gender; (D) primary tumor differential grade; (E) SEER

historic stage; (F) AJCC stage; (G) primary tumor size; (H) lymph node status; (I) surgery for primary tumor; (J) AFP level; (K) fibrosis score.

Figure 7 Prognostic nomogram estimated by clinical characteristics for 1-year, 2-year, and

3-year OS in Klatskin tumor patients. (A) To get the nomogram, the factors lie on each

variable axis and is drawn up to determine the point value. A vertical line from the total point

scale to the probability scale is draw and the probability of 1-year, 2-year, or 3-year OS is

determined. The calibration curve for OS at (B) 1 years, (C) 2 years and (D) 3 years is shown. X-

axis is nomogram-predicted OS and y-axis is actual OS. (E) ROC curve analysis for predicting

the accuracy of the nomogram. 
Figure 1

Flowchart of the enrolled patients in the study according to inclusion and exclusion criterion.

Flowchart of the enrolled patients in the study according to inclusion and exclusion criterion.

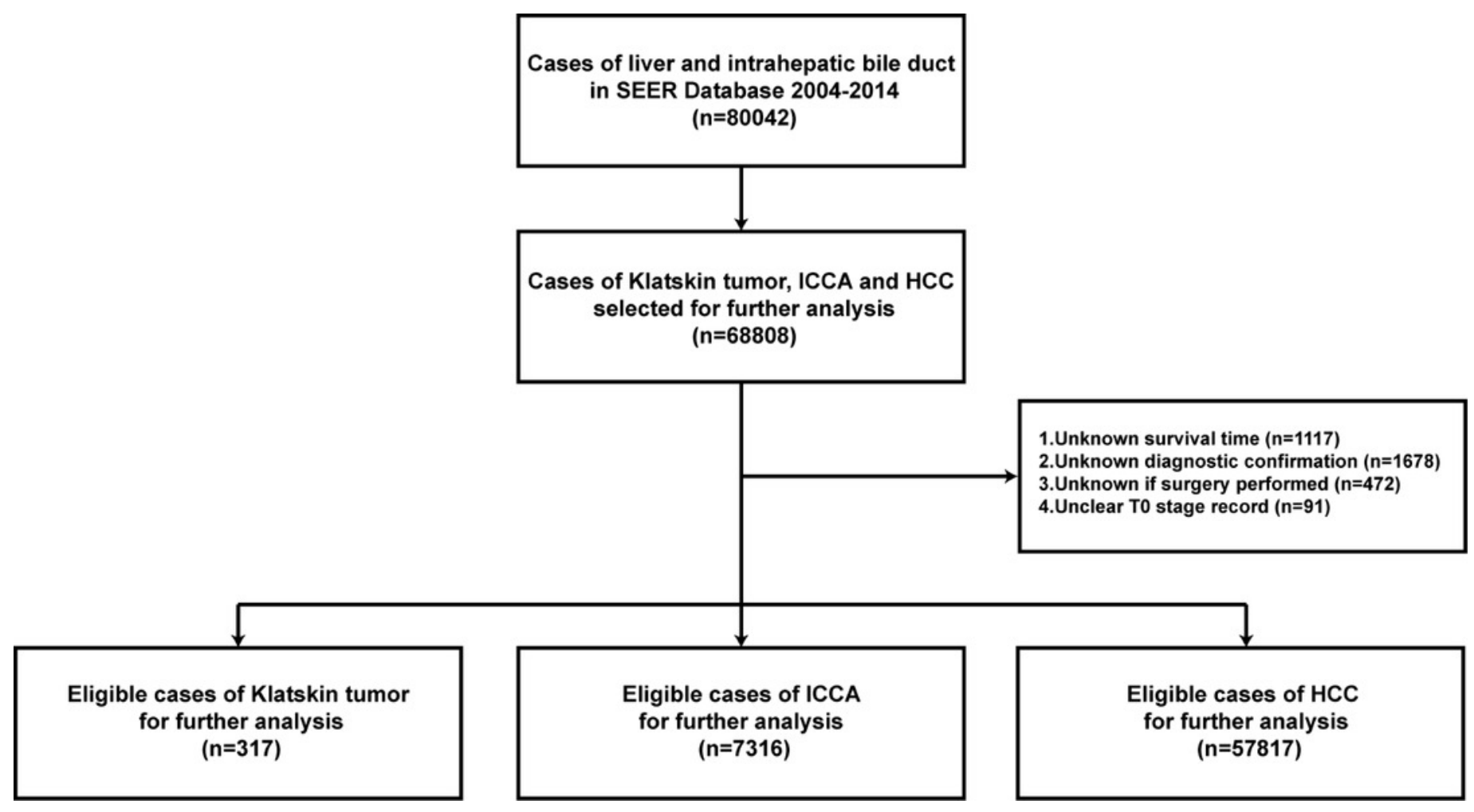


Figure 2

Kaplan-Meier curve of overall survival and the incidence trend

Overall survival (A) and cancer specific survival (B) according to histologic type of Klatskin tumors, ICCA or HCC before propensity score matching. The incidence trend for Klatskin tumor (C), ICCA (D) and HCC (E).

A

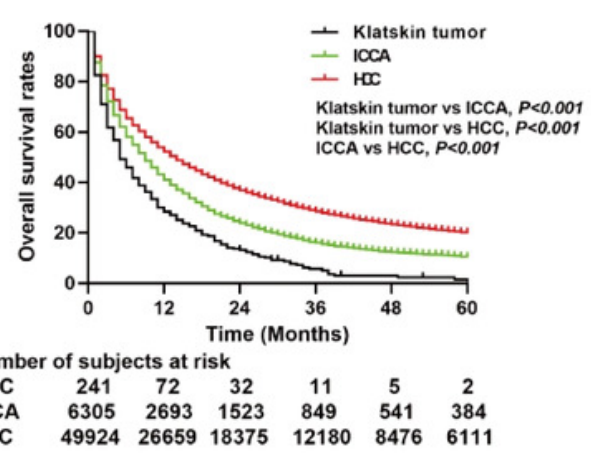

B

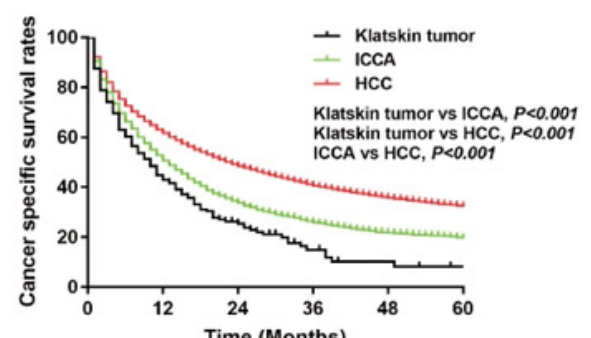

Number of subjects at risk

$\begin{array}{lcccccc}\text { Number of subjects at risk } \\ \text { KCC } & 241 & 72 & 32 & 11 & 5 & 2 \\ \text { ICCA } & 6305 & 2693 & 1524 & 849 & 541 & 384 \\ \text { HCC } & 49924 & 26659 & 18375 & 12180 & 8476 & 6111\end{array}$

$\begin{array}{lllllll}\text { HCC } & 49924 & 26659 & 18375 & 12180 & 8476 & 6111\end{array}$
C

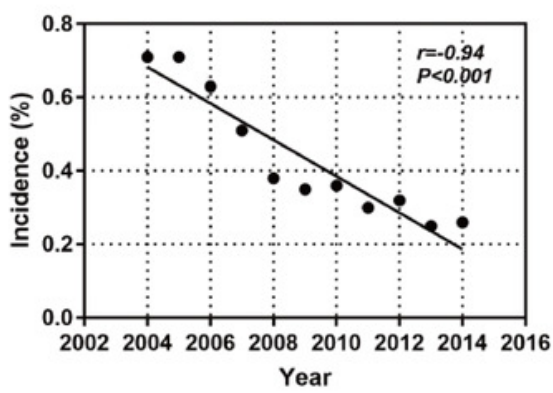

D

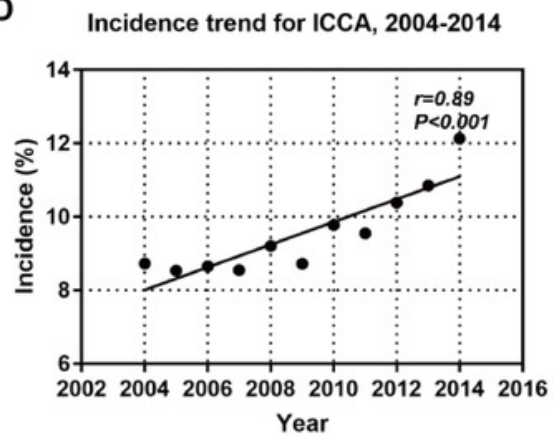

E Incidence trend for HCC, 2004-2014

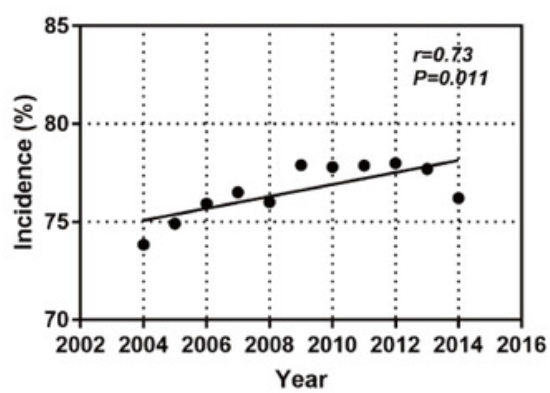




\section{Figure 3}

Kaplan-Meier curve of overall survival in Klatskin tumor, ICCA and HCC patients before propensity score matching stratified by

(A) age at diagnosis; (B) race; (C) gender; (D) primary tumor differential grade; (E) SEER historic stage; (F) AJCC stage; (G) primary tumor size; (H) lymph node status; (I) surgery for primary tumor; (J) AFP level; (K) fibrosis score.

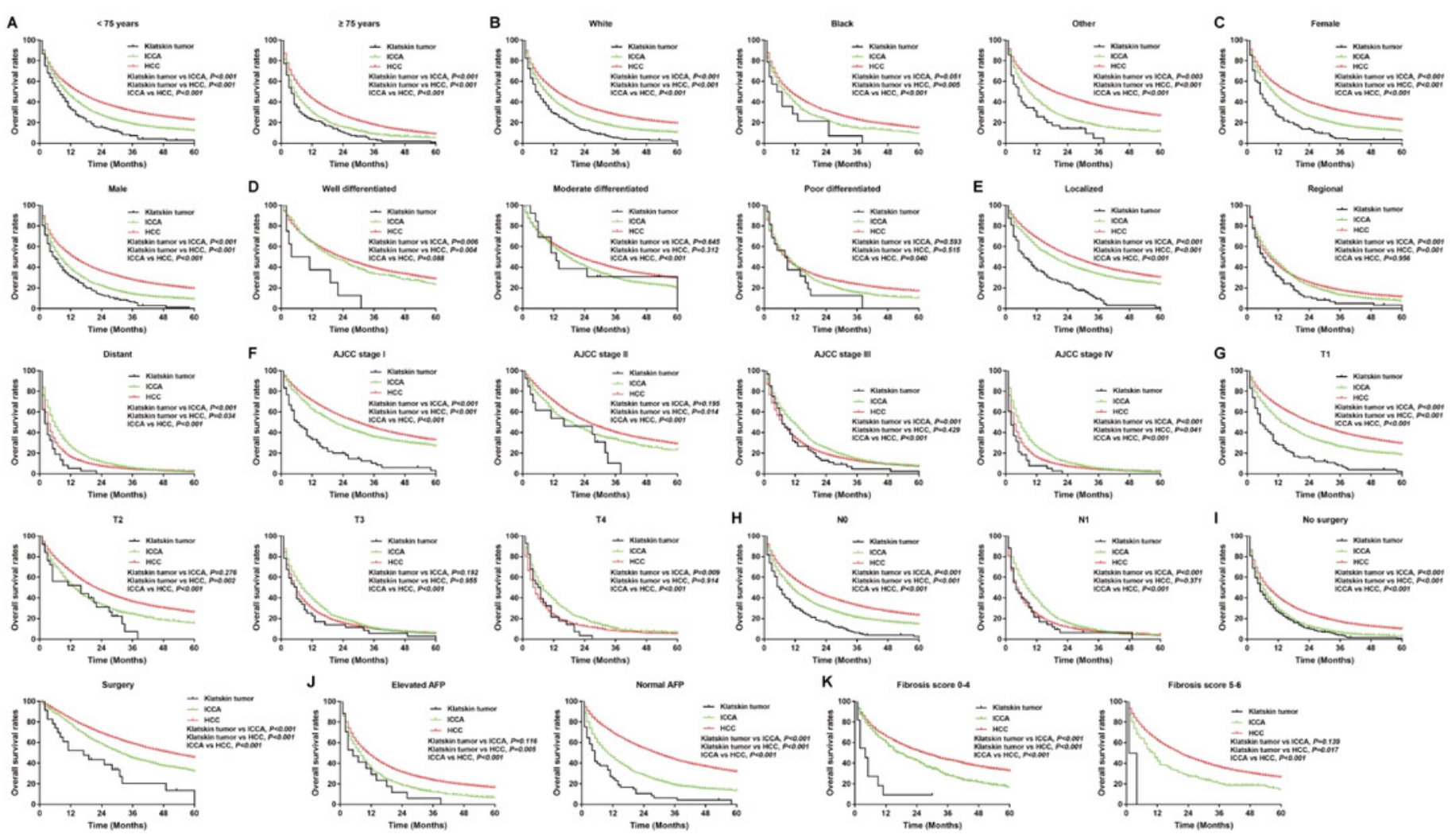


Figure 4

\section{Kaplan-Meier plot and log-rank test}

Overall survival (A) and cancer specific survival (B) according to histologic type of Klatskin tumors, ICCA or HCC after propensity score matching.

A

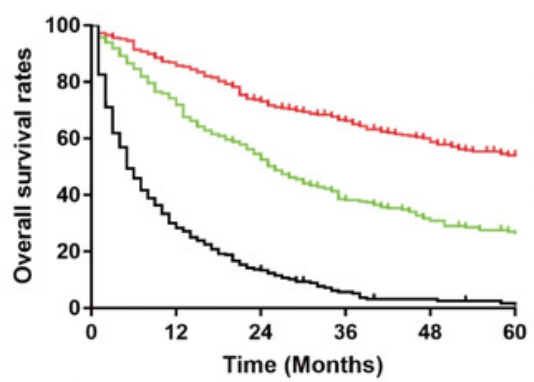

Number of subjects at risk

\begin{tabular}{lcccccc}
\multicolumn{7}{l}{ Number of subjects at risk } \\
KCC & 241 & 72 & 32 & 11 & 5 & 2 \\
ICCA & 305 & 223 & 162 & 96 & 69 & 52 \\
HCC & 314 & 270 & 225 & 180 & 146 & 115
\end{tabular}

$\mathrm{HCC}$

$\begin{array}{llllll}314 & 270 & 225 & 180 & 146 & 115\end{array}$
- Klatskin tumor

+ ICCA

Klatskin tumor vs ICCA, $P<0.001$ Klatskin tumor vs $\mathrm{HCC}, P<0.001$ ICCA vs HCC, $P<0.001$
B

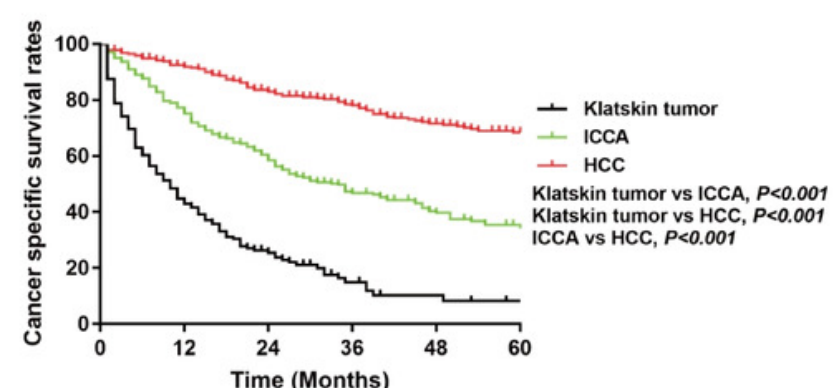

Number of subjects at risk

$\begin{array}{llllccc}\text { Kumb } & 241 & 72 & 32 & 11 & 5 & 2 \\ \text { ICCA } & 305 & 223 & 162 & 96 & 69 & 52 \\ \text { HCC } & 314 & 270 & 225 & 180 & 146 & 115\end{array}$




\section{Figure 5}

Kaplan-Meier curve of overall survival in Klatskin tumor, ICCA and HCC patients after propensity score matching stratified by

(A) age at diagnosis; (B) race; (C) gender; (D) primary tumor differential grade; (E) SEER historic stage; (F) AJCC stage; (G) primary tumor size; (H) lymph node status; (I) surgery for primary tumor; (J) AFP level; (K) fibrosis score .
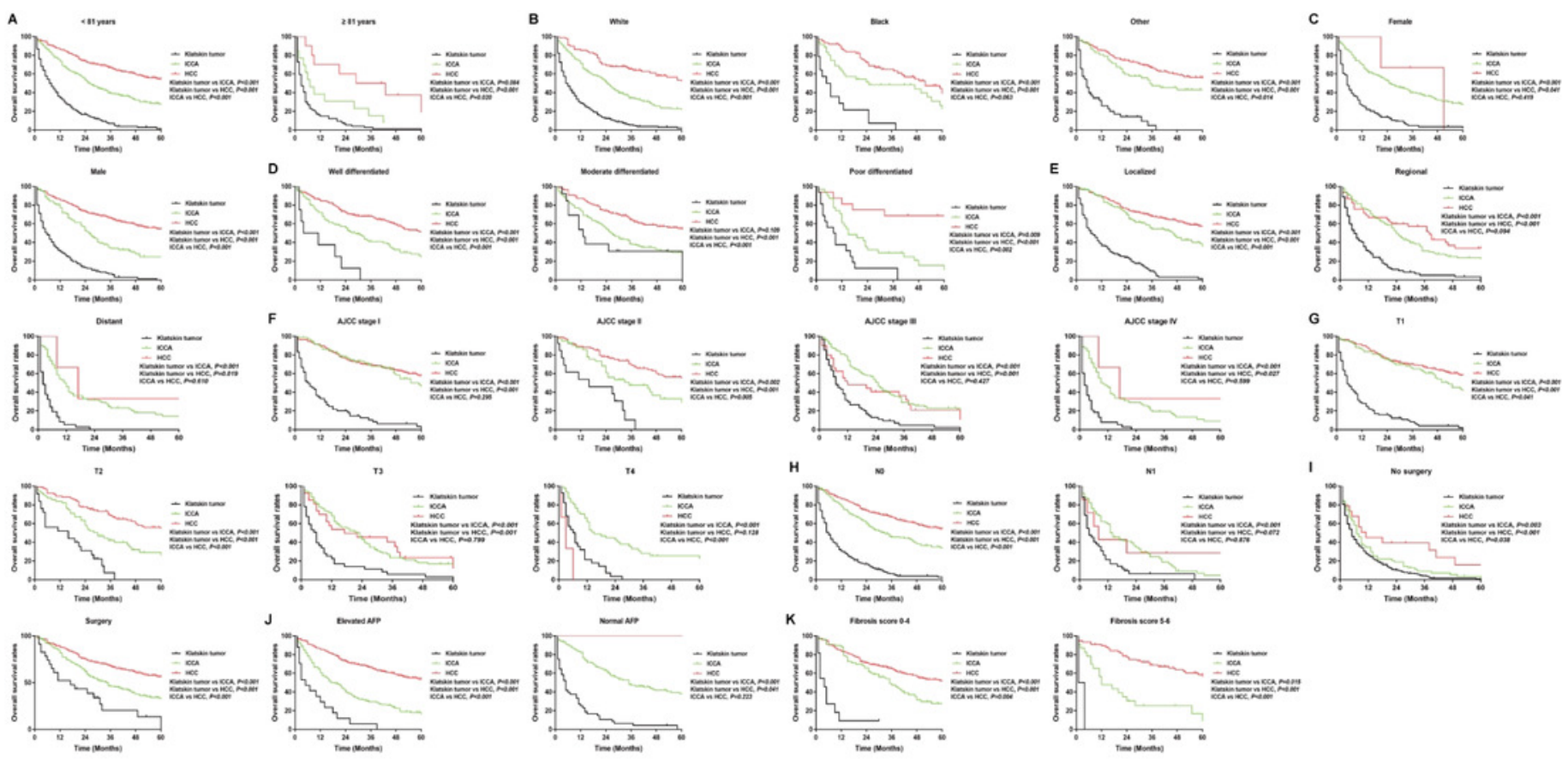
Figure 6

Kaplan-Meier curve of overall survival in Klatskin tumor patients stratified by

(A) age at diagnosis; (B) race; (C) gender; (D) primary tumor differential grade; (E) SEER historic stage; (F) AJCC stage; (G) primary tumor size; (H) lymph node status; (I) surgery for primary tumor; (J) AFP level; (K) fibrosis score.
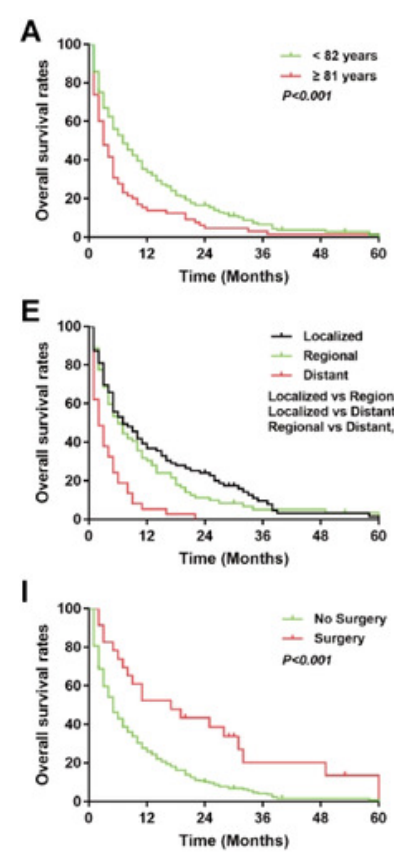

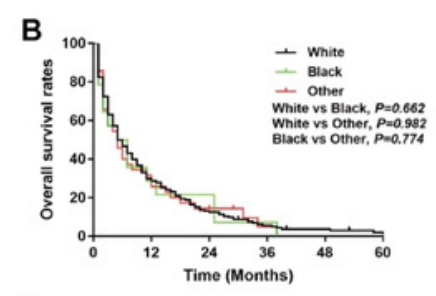

F
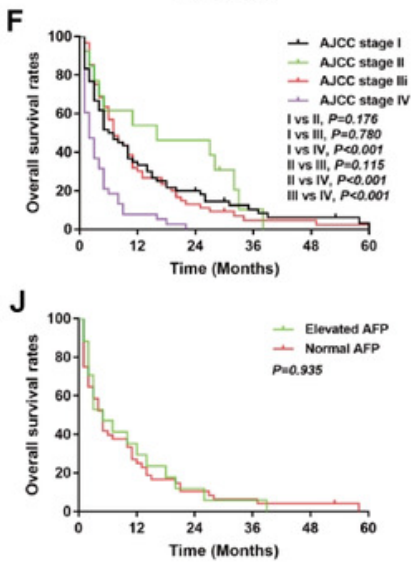
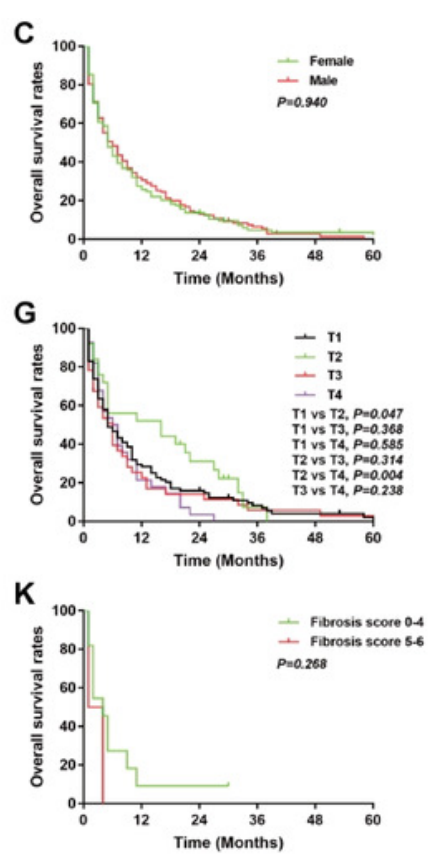
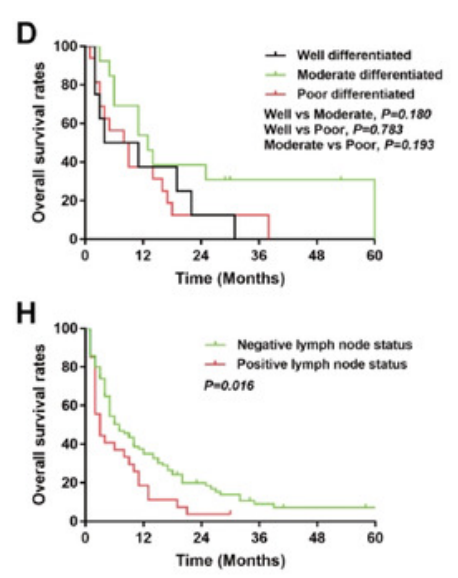


\section{Figure 7}

Prognostic nomogram estimated by clinical characteristics for 1-year, 2-year, and 3-year OS in Klatskin tumor patients.

(A) To get the nomogram, the factors lie on each variable axis and is drawn up to determine the point value. A vertical line from the total point scale to the probability scale is draw and the probability of 1-year, 2-year, or 3-year OS is determined. The calibration curve for OS at (B) 1 years, (C) 2 years and (D) 3 years is shown. X-axis is nomogram-predicted OS and $y$ axis isactual OS. (E) ROC curve analysis for predicting the accuracy of the nomogram.
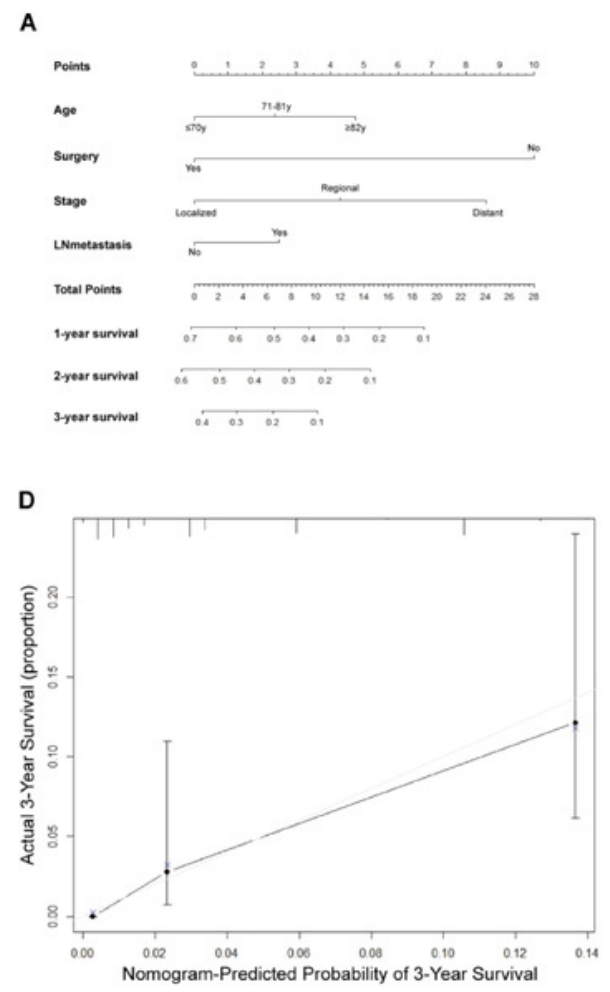

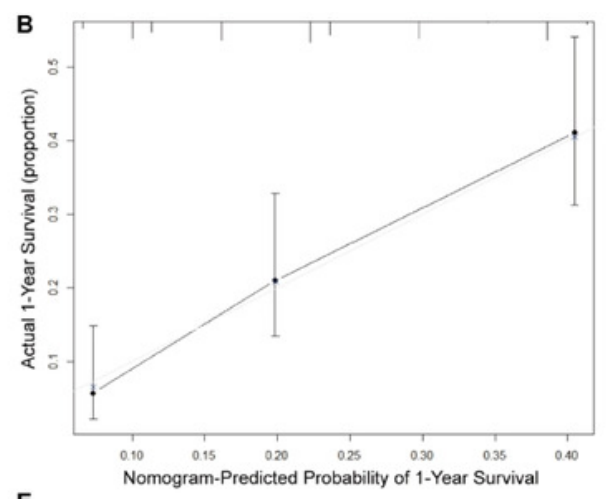

E

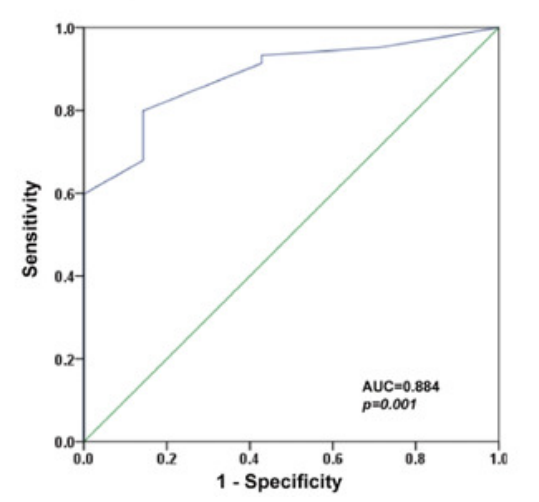

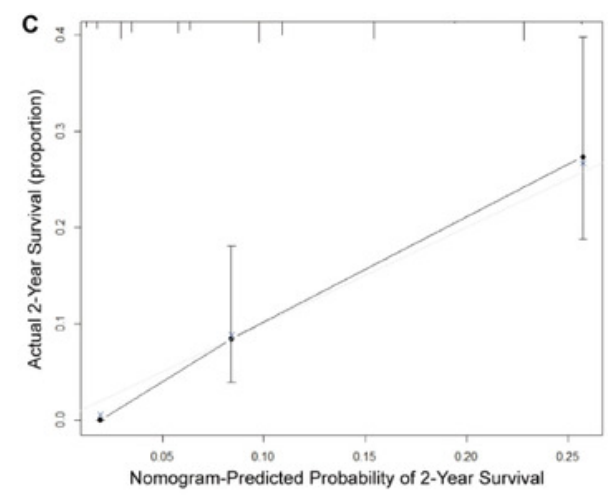




\section{Table $\mathbf{1}$ (on next page)}

Characteristics of patients with Klatskin tumors, ICCA and HCC in the SEER database, 2004-2014

a. Including divorced, separated, single (never married), unmarried or having a domestic partner and widowed. b. Including American Indian/Alaskan Native and Asian/Pacific Islander. Abbreviations: AJCC, American Joint Committee on Cancer; ICCA, Intrahepatic Cholangiocarcinoma; HCC, hepatocellular carcinoma. 
1 Table 1 Characteristics of patients with Klatskin tumors, ICCA and HCC in the SEER database, 2004-2014

\begin{tabular}{|c|c|c|c|c|c|}
\hline \multirow[b]{2}{*}{ Characteristics } & \multicolumn{5}{|c|}{ Histologic type } \\
\hline & $\begin{array}{l}\text { Klatskin } \\
\text { tumor }\end{array}$ & ICCA & $\mathrm{HCC}$ & Total & p-value \\
\hline Number & 317 & 7316 & 57817 & 65450 & \\
\hline Age (years) & $72.78 \pm 13.29$ & $66.76 \pm 12.99$ & $63.62 \pm 11.48$ & & $<0.001$ \\
\hline \multicolumn{6}{|l|}{ Marital status } \\
\hline Married & $166(52.4 \%)$ & $4163(56.9 \%)$ & $29315(50.7 \%)$ & $33644(51.4 \%)$ & $<0.001$ \\
\hline Not married ${ }^{\mathrm{a}}$ & $137(43.2 \%)$ & $2849(38.9 \%)$ & $25778(44.6 \%)$ & $28764(43.9 \%)$ & \\
\hline Unknown & $14(4.4 \%)$ & $304(4.2 \%)$ & $2724(4.7 \%)$ & $3042(4.7 \%)$ & \\
\hline \multicolumn{6}{|l|}{ Race } \\
\hline White & $252(79.5 \%)$ & $5729(78.3 \%)$ & $39500(68.3 \%)$ & $45481(69.5 \%)$ & $<0.001$ \\
\hline Black & $21(6.6 \%)$ & $589(8.0 \%)$ & $7832(13.5 \%)$ & $8442(12.9 \%)$ & \\
\hline Other $^{b}$ & $44(13.9 \%)$ & $987(13.5 \%)$ & 10294(17.8\%) & $11325(17.3 \%)$ & \\
\hline Unknown & $0(0 \%)$ & $11(0.2 \%)$ & $191(0.4 \%)$ & $202(0.3 \%)$ & \\
\hline \multicolumn{6}{|l|}{ Gender } \\
\hline Female & $141(44.5 \%)$ & $3669(50.2 \%)$ & $13374(23.1 \%)$ & $17184(26.3 \%)$ & $<0.001$ \\
\hline Male & $176(55.5 \%)$ & $3647(49.8 \%)$ & $44443(76.9 \%)$ & $48266(73.7 \%)$ & \\
\hline \multicolumn{6}{|l|}{ Grade } \\
\hline Well differentiated & $9(2.8 \%)$ & $319(4.4 \%)$ & $6819(11.8 \%)$ & $7147(10.9 \%)$ & $<0.001$ \\
\hline Moderate & $15(4.7 \%)$ & $1435(19.6 \%)$ & $9140(15.8 \%)$ & $10590(16.2 \%)$ & \\
\hline Poor & $16(5.0 \%)$ & $1268(17.3 \%)$ & $4533(7.8 \%)$ & $5817(8.9 \%)$ & \\
\hline Anaplastic & $1(0.3 \%)$ & $39(0.5 \%)$ & $398(0.7 \%)$ & $438(0.7 \%)$ & \\
\hline Unknown & $276(87.2 \%)$ & $4255(58.2 \%)$ & $36927(63.9 \%)$ & $41458(63.3 \%)$ & \\
\hline \multicolumn{6}{|l|}{ SEER historic stage } \\
\hline Localized & $99(31.2 \%)$ & $1963(26.8 \%)$ & $28758(49.7 \%)$ & $30820(47.1 \%)$ & $<0.001$ \\
\hline Regional & $101(31.9 \%)$ & $2208(30.2 \%)$ & $16106(27.9 \%)$ & $18415(28.1 \%)$ & \\
\hline
\end{tabular}




$\begin{array}{ccccc}\text { Distant } & 51(16.1 \%) & 2402(32.8 \%) & 8699(15.0 \%) & 11152(17.0 \%) \\ \text { Unknown } & 66(20.8 \%) & 743(10.2 \%) & 4254(7.4 \%) & 5063(7.8 \%)\end{array}$

\section{AJCC stage}

\begin{tabular}{|c|c|c|c|c|c|}
\hline I & $76(24.0 \%)$ & $1388(19.0 \%)$ & $19005(32.9 \%)$ & $20469(31.3 \%)$ & $<0.001$ \\
\hline II & $14(4.4 \%)$ & $476(6.5 \%)$ & $9865(17.1 \%)$ & $10355(15.8 \%)$ & \\
\hline III & $72(22.7 \%)$ & $1622(22.2 \%)$ & $11569(20.0 \%)$ & $13263(20.3 \%)$ & \\
\hline IV & $52(16.4 \%)$ & $2405(32.9 \%)$ & $8331(14.4 \%)$ & $10788(16.5 \%)$ & \\
\hline Unknown & $103(32.5 \%)$ & $1425(19.4 \%)$ & $9047(15.6 \%)$ & $10575(16.1 \%)$ & \\
\hline \multicolumn{6}{|l|}{ T category } \\
\hline $\mathrm{T} 1$ & $118(37.2 \%)$ & $2216(30.3 \%)$ & $22488(38.9 \%)$ & $24822(37.9 \%)$ & $<0.001$ \\
\hline $\mathrm{T} 2$ & $28(8.8 \%)$ & $826(11.3 \%)$ & $11855(20.5 \%)$ & $12709(19.4 \%)$ & \\
\hline $\mathrm{T} 3$ & $37(11.7 \%)$ & $1481(20.2 \%)$ & $12808(22.2 \%)$ & $14326(21.9 \%)$ & \\
\hline $\mathrm{T} 4$ & $35(11.0 \%)$ & $812(11.1 \%)$ & $2201(3.8 \%)$ & $3048(4.7 \%)$ & \\
\hline $\mathrm{Tx}$ & $99(31.3 \%)$ & $1981(27.1 \%)$ & $8465(14.6 \%)$ & $10545(16.1 \%)$ & \\
\hline \multicolumn{6}{|l|}{$\mathbf{N}$ category } \\
\hline No & $184(58.0 \%)$ & $4441(60.7 \%)$ & $45479(78.7 \%)$ & $50104(76.6 \%)$ & $<0.001$ \\
\hline N1 & $56(17.7 \%)$ & $1396(19.1 \%)$ & $3752(6.5 \%)$ & $5204(8.0 \%)$ & \\
\hline $\mathrm{Nx}$ & $77(24.3 \%)$ & $1479(20.2 \%)$ & $8586(14.8 \%)$ & $10142(15.4 \%)$ & \\
\hline
\end{tabular}

\section{Local treatment of}

the primary tumor

\begin{tabular}{|c|c|c|c|c|c|}
\hline None & $293(92.4 \%)$ & $5721(78.2 \%)$ & $43690(75.6 \%)$ & $49704(75.9 \%)$ & $<0.001$ \\
\hline Local destruction & $0(0.0 \%)$ & $154(2.1 \%)$ & $5936(10.3 \%)$ & $6090(9.3 \%)$ & \\
\hline Surgery & $24(7.6 \%)$ & $1441(19.7 \%)$ & $8191(14.1 \%)$ & $9656(14.8 \%)$ & \\
\hline \multicolumn{6}{|l|}{ Alpha fetoprotein } \\
\hline Elevated & $22(6.9 \%)$ & $967(13.2 \%)$ & $33014(57.1 \%)$ & $34003(52.0 \%)$ & $<0.001$ \\
\hline Normal & $62(19.6 \%)$ & $2297(31.4 \%)$ & $10483(18.1 \%)$ & $12842(19.6 \%)$ & \\
\hline Unknown & $233(73.5 \%)$ & $4052(55.4 \%)$ & $14320(24.8 \%)$ & $18605(28.4 \%)$ & \\
\hline
\end{tabular}




\section{Fibrosis score}

\begin{tabular}{|c|c|c|c|c|}
\hline $0-4$ & $14(4.4 \%)$ & $450(6.2 \%)$ & $2781(4.8 \%)$ & $3245(5.0 \%)$ \\
\hline $5-6$ & $2(0.6 \%)$ & $263(3.6 \%)$ & $11562(20.0 \%)$ & $11827(18.0 \%)$ \\
\hline Unknown & $301(95.0 \%)$ & $6603(90.2 \%)$ & $43474(75.2 \%)$ & $50378(77.0 \%)$ \\
\hline
\end{tabular}

2 a. Including divorced, separated, single (never married), unmarried or having a domestic partner and widowed.

3 b. Including American Indian/Alaskan Native and Asian/Pacific Islander.

4 Abbreviations: AJCC, American Joint Committee on Cancer; ICCA, Intrahepatic Cholangiocarcinoma; HCC, 5 hepatocellular carcinoma. 


\section{Table 2 (on next page)}

Univariate and multivariate Cox proportional hazard analyses of the association of clinical characteristics with overall survival rates in patients with Klatskin tumors, ICCA and HCC

$\mathrm{Cl}$ : confidence interval. Abbreviations: ICCA, Intrahepatic Cholangiocarcinoma; HCC, hepatocellular carcinoma. 
1 Table 2 Univariate and multivariate Cox proportional hazard analyses of the association of clinical characteristics

2 with overall survival rates in patients with Klatskin tumors, ICCA and HCC

\begin{tabular}{|c|c|c|c|c|}
\hline Variance & Univariate HR $(95 \% \mathrm{CI})$ & $\mathrm{P}$ value & Multivariate HR $(95 \% \mathrm{CI})$ & $\mathrm{P}$ value \\
\hline \multicolumn{5}{|l|}{ Age } \\
\hline$<75$ years & 1 & & 1 & \\
\hline$\geq 75$ years & $1.519(1.489-1.550)$ & $<0.001$ & $1.414(1.385-1.443)$ & $<0.001$ \\
\hline \multicolumn{5}{|l|}{ Race } \\
\hline White & 1 & & 1 & \\
\hline Black & $1.127(1.099-1.156)$ & $<0.001$ & $1.080(1.053-1.108)$ & $<0.001$ \\
\hline Other & $0.820(0.801-0.839)$ & $<0.001$ & $0.830(0.811-0.850)$ & $<0.001$ \\
\hline \multicolumn{5}{|l|}{ Gender } \\
\hline Female & 1 & & 1 & \\
\hline Male & $1.051(1.031-1.071)$ & $<0.001$ & $1.088(1.067-1.110)$ & $<0.001$ \\
\hline \multicolumn{5}{|l|}{ Grade } \\
\hline Well differentiated & 1 & & 1 & \\
\hline Moderate & $1.029(0.993-1.065)$ & 0.113 & $1.159(1.119-1.200)$ & $<0.001$ \\
\hline Poor & $1.694(1.630-1.760)$ & $<0.001$ & $1.496(1.438-1.556)$ & $<0.001$ \\
\hline Anaplastic & $1.763(1.589-1.956)$ & $<0.001$ & $1.561(1.407-1.733)$ & $<0.001$ \\
\hline \multicolumn{5}{|l|}{ SEER historic stage } \\
\hline Localized & 1 & & 1 & \\
\hline Regional & $1.940(1.901-1.980)$ & $<0.001$ & $1.279(1.245-1.314)$ & $<0.001$ \\
\hline Distant & $3.456(3.374-3.540)$ & $<0.001$ & $1.527(1.396-1.671)$ & $<0.001$ \\
\hline \multicolumn{5}{|l|}{ AJCC stage } \\
\hline I & 1 & & 1 & \\
\hline II & $1.019(0.991-1.048)$ & 0.181 & $1.000(0.942-1.062)$ & 0.992 \\
\hline III & $2.340(2.284-2.398)$ & $<0.001$ & $1.296(1.235-1.360)$ & $<0.001$ \\
\hline IV & $3.809(3.711-3.910)$ & $<0.001$ & $1.545(1.404-1.700)$ & $<0.001$ \\
\hline
\end{tabular}




\section{Stage T}

$\mathrm{T} 1$

$\mathrm{T} 2$

T3

$\mathrm{T} 4$

Stage $\mathbf{N}$

N0

N1
1

$1.010(0.985-1.035)$

$2.271(2.221-2.323)$

$2.462(2.366-2.561)$
1.996(1.937-2.056)
$<0.001$

1

0.951(0.902-1.002)

0.059

$1.249(1.200-1.300) \quad<0.001$

$1.221(1.159-1.285)$

$<0.001$

\section{Local treatment of}

\section{the primary tumor}

None

Local destruction

Surgery

\section{Alpha fetoprotein}

Elevated

Normal

\section{Fibrosis score}

$$
\begin{aligned}
& 0-4 \\
& 5-6
\end{aligned}
$$

Histologic type

Klatskin tumor

ICCA

0.674(0.601-0.756)

$<0.001$

$0.726(0.647-0.814)$

$<0.001$

HCC

$$
\begin{array}{ll}
0.387(0.375-0.400) & <0.001 \\
0.237(0.230-0.244) & <0.001
\end{array}
$$$$
0.521(0.504-0.538)
$$$$
<0.001
$$

$0.311(0.301-0.322)$

$<0.001$

$0.642(0.627-0.657) \quad<0.001$

$0.731(0.714-0.749)$

$<0.001$

1.114(1.065-1.167)

$<0.001$

0.962(0.918-1.007)

0.100

3 CI: confidence interval.

4 Abbreviations: ICCA, Intrahepatic Cholangiocarcinoma; HCC, hepatocellular carcinoma. 


\section{Table 3 (on next page)}

Characteristics of patients with Klatskin tumors, ICCA and HCC after propensity score matching in the SEER database, 2004-2014

a. Including divorced, separated, single (never married), unmarried or having a domestic partner and widowed. b. Including American Indian/Alaskan Native and Asian/Pacific Islander. Abbreviations: AJCC, American Joint Committee on Cancer; ICCA, Intrahepatic Cholangiocarcinoma; HCC, hepatocellular carcinoma. 
1 Table 3 Characteristics of patients with Klatskin tumors, ICCA and HCC after propensity score matching in the

2 SEER database, 2004-2014

\begin{tabular}{|c|c|c|c|c|c|}
\hline \multirow{2}{*}{ Characteristics } & \multicolumn{5}{|c|}{ Histologic type } \\
\hline & $\begin{array}{l}\text { Klatskin } \\
\text { tumor }\end{array}$ & ICCA & $\mathrm{HCC}$ & Total & $\mathrm{p}$-value \\
\hline Number & 317 & 317 & 317 & 951 & \\
\hline Age (years) & $72.78 \pm 13.29$ & $59.57 \pm 13.14$ & $58.73 \pm 11.36$ & & $<0.001$ \\
\hline \multicolumn{6}{|l|}{ Marital status } \\
\hline Married & $166(52.4 \%)$ & $213(67.2 \%)$ & $144(45.4 \%)$ & $523(55.0 \%)$ & $<0.001$ \\
\hline Not married ${ }^{\mathrm{a}}$ & $137(43.2 \%)$ & $97(30.6 \%)$ & $153(48.3 \%)$ & $387(40.7 \%)$ & \\
\hline Unknown & $14(4.4 \%)$ & $7(2.2 \%)$ & $20(6.3 \%)$ & $41(4.3 \%)$ & \\
\hline \multicolumn{6}{|l|}{ Race } \\
\hline White & $252(79.5 \%)$ & $225(71.0 \%)$ & $88(27.8 \%)$ & $565(59.4 \%)$ & $<0.001$ \\
\hline Black & $21(6.6 \%)$ & $37(11.7 \%)$ & $63(19.9 \%)$ & $121(12.7 \%)$ & \\
\hline Other $^{b}$ & $44(13.9 \%)$ & $55(17.3 \%)$ & $157(49.5 \%)$ & $256(26.9 \%)$ & \\
\hline Unknown & $0(0 \%)$ & $0(0 \%)$ & $9(2.8 \%)$ & $9(1.0 \%)$ & \\
\hline \multicolumn{6}{|l|}{ Gender } \\
\hline Female & $141(44.5 \%)$ & $222(70.0 \%)$ & $3(0.9 \%)$ & $366(38.5 \%)$ & $<0.001$ \\
\hline Male & $176(55.5 \%)$ & $95(30.0 \%)$ & $314(99.1 \%)$ & $585(61.5 \%)$ & \\
\hline \multicolumn{6}{|l|}{ Grade } \\
\hline Well differentiated & $9(2.8 \%)$ & $98(30.9 \%)$ & $157(49.5 \%)$ & $264(27.8 \%)$ & $<0.001$ \\
\hline Moderate & $15(4.7 \%)$ & $187(59.0 \%)$ & $144(45.5 \%)$ & $346(36.4 \%)$ & \\
\hline Poor & $16(5.0 \%)$ & $32(10.1 \%)$ & $16(5.0 \%)$ & $64(6.7 \%)$ & \\
\hline Anaplastic & $1(0.3 \%)$ & $0(0.0 \%)$ & $0(0.0 \%)$ & $1(0.1 \%)$ & \\
\hline Unknown & $276(87.2 \%)$ & $0(0.0 \%)$ & $0(0.0 \%)$ & $276(29.0 \%)$ & \\
\hline \multicolumn{6}{|l|}{ SEER historic stage } \\
\hline Localized & $99(31.2 \%)$ & $125(39.4 \%)$ & $266(83.9 \%)$ & $490(51.5 \%)$ & $<0.001$ \\
\hline
\end{tabular}




$\begin{array}{ccccc}\text { Regional } & 101(31.9 \%) & 101(31.9 \%) & 47(14.8 \%) & 249(26.2 \%) \\ \text { Distant } & 51(16.1 \%) & 76(24.0 \%) & 4(1.3 \%) & 131(13.8 \%) \\ \text { Unknown } & 66(20.8 \%) & 15(4.7 \%) & 0(0.0 \%) & 81(8.5 \%)\end{array}$

AJCC stage

\begin{tabular}{|c|c|c|c|c|c|}
\hline $\mathrm{I}$ & $76(24.0 \%)$ & $75(23.7 \%)$ & $189(59.6 \%)$ & $340(35.8 \%)$ & $<0.001$ \\
\hline II & $14(4.4 \%)$ & $42(13.2 \%)$ & $93(29.3 \%)$ & $149(15.7 \%)$ & \\
\hline III & $72(22.7 \%)$ & $103(32.5 \%)$ & $30(9.5 \%)$ & $205(21.6 \%)$ & \\
\hline IV & $52(16.4 \%)$ & $66(20.8 \%)$ & $4(1.3 \%)$ & $122(12.8 \%)$ & \\
\hline Unknown & $103(32.5 \%)$ & $31(9.8 \%)$ & $1(0.3 \%)$ & $135(14.1 \%)$ & \\
\hline \multicolumn{6}{|l|}{ T category } \\
\hline $\mathrm{T} 1$ & $118(37.2 \%)$ & $89(28.1 \%)$ & $191(60.3 \%)$ & $398(41.9 \%)$ & $<0.001$ \\
\hline $\mathrm{T} 2$ & $28(8.8 \%)$ & $57(18.0 \%)$ & $94(29.7 \%)$ & $179(18.8 \%)$ & \\
\hline $\mathrm{T} 3$ & $37(11.7 \%)$ & $87(27.4 \%)$ & $27(8.5 \%)$ & $151(15.9 \%)$ & \\
\hline $\mathrm{T} 4$ & $35(11.0 \%)$ & $47(14.8 \%)$ & $4(1.3 \%)$ & $86(9.0 \%)$ & \\
\hline $\mathrm{Tx}$ & $99(31.3 \%)$ & $37(11.7 \%)$ & $1(0.2 \%)$ & $137(14.4 \%)$ & \\
\hline
\end{tabular}

N category

\begin{tabular}{|c|c|c|c|c|}
\hline No & $184(58.0 \%)$ & $223(70.3 \%)$ & $308(97.2 \%)$ & $715(75.2 \%)$ \\
\hline N1 & $56(17.7 \%)$ & $70(22.1 \%)$ & $8(2.5 \%)$ & $134(14.1 \%)$ \\
\hline $\mathrm{Nx}$ & $77(24.3 \%)$ & $24(7.6 \%)$ & $1(0.3 \%)$ & $102(10.7 \%)$ \\
\hline
\end{tabular}

\section{Local treatment of}

the primary tumor

\begin{tabular}{|c|c|c|c|c|c|}
\hline None & $293(92.4 \%)$ & $72(22.7 \%)$ & $20(6.3 \%)$ & $385(40.5 \%)$ & $<0.001$ \\
\hline Local destruction & $0(0.0 \%)$ & $10(3.2 \%)$ & $40(12.6 \%)$ & $50(5.3 \%)$ & \\
\hline Surgery & $24(7.6 \%)$ & $235(74.1 \%)$ & $257(81.1 \%)$ & $516(54.2 \%)$ & \\
\hline \multicolumn{6}{|l|}{ Alpha fetoprotein } \\
\hline Elevated & $22(6.9 \%)$ & $161(50.8 \%)$ & $316(99.7 \%)$ & $499(52.5 \%)$ & $<0.001$ \\
\hline Normal & $62(19.6 \%)$ & $137(43.2 \%)$ & $1(0.3 \%)$ & $200(21.0 \%)$ & \\
\hline
\end{tabular}




$$
\begin{array}{llll}
\text { Unknown } & 233(73.5 \%) & 19(6.0 \%) & 0(0 \%)
\end{array}
$$

\section{Fibrosis score}

\begin{tabular}{|c|c|c|c|c|}
\hline $0-4$ & $14(4.4 \%)$ & $81(25.6 \%)$ & $229(72.2 \%)$ & $324(34.1 \%)$ \\
\hline $5-6$ & $2(0.6 \%)$ & $24(7.6 \%)$ & $77(24.3 \%)$ & $103(10.8 \%)$ \\
\hline Unknown & $301(95.0 \%)$ & $212(66.8 \%)$ & $11(3.5 \%)$ & $524(55.1 \%)$ \\
\hline
\end{tabular}

3 a. Including divorced, separated, single (never married), unmarried or having a domestic partner and widowed.

4 b. Including American Indian/Alaskan Native and Asian/Pacific Islander.

5 Abbreviations: AJCC, American Joint Committee on Cancer; ICCA, Intrahepatic Cholangiocarcinoma; HCC, 6 hepatocellular carcinoma. 


\section{Table 4 (on next page)}

Univariate and multivariate Cox proportional hazard analyses in patients with Klatskin tumors, ICCA and HCC after propensity score matching

Cl: confidence interval. Abbreviations: ICCA, Intrahepatic Cholangiocarcinoma; HCC, hepatocellular carcinoma. 
1 Table 4 Univariate and multivariate Cox proportional hazard analyses of the association of clinical characteristics

2 with overall survival rates in patients with Klatskin tumors, ICCA and HCC after propensity score matching

\begin{tabular}{|c|c|c|c|c|}
\hline Variance & Univariate HR $(95 \% \mathrm{CI})$ & $P$ value & Multivariate HR $(95 \% \mathrm{CI})$ & $P$ value \\
\hline \multicolumn{5}{|l|}{ Age } \\
\hline$<81$ years & 1 & & 1 & \\
\hline$\geq 81$ years & $3.409(2.801-4.148)$ & $<0.001$ & $1.736(1.396-2.157)$ & $<0.001$ \\
\hline \multicolumn{5}{|l|}{ Race } \\
\hline White & 1 & & 1 & \\
\hline Black & $0.610(0.481-0.774)$ & $<0.001$ & $1.223(0.945-1.583)$ & 0.126 \\
\hline Other & $0.503(0.420-0.604)$ & $<0.001$ & $0.976(0.796-1.198)$ & 0.819 \\
\hline \multicolumn{5}{|l|}{ Gender } \\
\hline Female & 1 & & 1 & \\
\hline Male & $0.679(0.585-0.789)$ & $<0.001$ & $1.057(0.878-1.271)$ & 0.559 \\
\hline \multicolumn{5}{|l|}{ Grade } \\
\hline Well differentiated & 1 & & 1 & \\
\hline Moderate & $1.029(0.843-1.257)$ & 0.778 & $0.872(0.691-1.100)$ & 0.249 \\
\hline Poor & $1.470(1.072-2.016)$ & 0.017 & $0.966(0.669-1.396)$ & 0.854 \\
\hline Anaplastic & $6.219(0.867-44.587)$ & 0.069 & $2.332(0.279-19.504)$ & 0.435 \\
\hline \multicolumn{5}{|l|}{ SEER historic stage } \\
\hline Localized & 1 & & 1 & \\
\hline Regional & $1.954(1.635-2.336)$ & $<0.001$ & $1.141(0.860-1.513)$ & 0.361 \\
\hline Distant & $3.075(2.479-3.813)$ & $<0.001$ & $1.362(0.711-2.606)$ & 0.351 \\
\hline \multicolumn{5}{|l|}{ AJCC stage } \\
\hline I & 1 & & 1 & \\
\hline II & $0.862(0.672-1.105)$ & 0.241 & $1.273(0.720-2.250)$ & 0.407 \\
\hline III & $2.085(1.700-2.557)$ & $<0.001$ & $1.376(0.875-2.163)$ & 0.167 \\
\hline IV & $3.643(2.882-4.604)$ & $<0.001$ & $1.556(0.755-3.205)$ & 0.231 \\
\hline
\end{tabular}




\section{Stage T}

$\mathrm{T} 1$

$\mathrm{T} 2$

T3

$\mathrm{T} 4$

Stage N

N0

N1
1

0.855(0.686-1.067)

$1.754(1.416-2.172)$

$2.181(1.688-2.818)$
1

2.431(1.986-2.976)
$<0.001$

1

0.166

$0.787(0.472-1.314)$

0.360

$1.060(0.730-1.539)$

0.760

$1.041(0.695-1.560)$

0.844

\section{Local treatment of}

the primary tumor

None

Local destruction

Surgery

Alpha fetoprotein

Elevated

Normal

Fibrosis score

0-4

5-6

Histologic type

Klatskin tumor

1

ICCA

$0.277(0.232-0.331)$

$<0.001$

$0.494(0.312-0.785)$

0.003

HCC

$0.136(0.111-0.167)$

$<0.001$

$0.251(0.138-0.455)$

$<0.001$

3

CI: confidence interval.

4 Abbreviations: ICCA, Intrahepatic Cholangiocarcinoma; HCC, hepatocellular carcinoma. 


\section{Table 5 (on next page)}

Univariate and multivariate Cox proportional hazard analyses of the association of clinical characteristics with overall survival rates in patients with Klatskin tumors

Cl: confidence interval. 
1 Table 5 Univariate and multivariate Cox proportional hazard analyses of the association of clinical characteristics

2 with overall survival rates in patients with Klatskin tumors

\begin{tabular}{|c|c|c|c|c|}
\hline \multirow{2}{*}{ Variance } & Univariate & \multirow{2}{*}{$P$ value } & Multivariate & \multirow{2}{*}{$P$ value } \\
\hline & Hazard ratio $(95 \% \mathrm{CI})$ & & Hazard ratio $(95 \% \mathrm{CI})$ & \\
\hline \multicolumn{5}{|l|}{ Age } \\
\hline$<82$ years & 1 & & 1 & \\
\hline$\geq 82$ years & $1.663(1.305-2.121)$ & $<0.001$ & $1.725(1.324-2.249)$ & $<0.001$ \\
\hline \multicolumn{5}{|l|}{ Race } \\
\hline White & 1 & & 1 & \\
\hline Black & $1.098(0.696-1.734)$ & 0.687 & $1.735(1.063-2.831)$ & 0.027 \\
\hline Other & $0.997(0.718-1.384)$ & 0.986 & $1.232(0.866-1.753)$ & 0.246 \\
\hline \multicolumn{5}{|l|}{ Gender } \\
\hline Female & 1 & & 1 & \\
\hline Male & $1.024(0.817-1.284)$ & 0.834 & $1.011(0.789-1.296)$ & 0.929 \\
\hline \multicolumn{5}{|l|}{ Grade } \\
\hline Well differentiated & 1 & & 1 & \\
\hline Moderate & $0.504(0.208-1.222)$ & 0.130 & $0.488(0.188-1.267)$ & 0.141 \\
\hline Poor & $0.875(0.386-1.984)$ & 0.749 & $0.716(0.295-1.739)$ & 0.461 \\
\hline Anaplastic & $1.335(0.169-10.570)$ & 0.784 & $3.911(0.370-41.325)$ & 0.257 \\
\hline \multicolumn{5}{|l|}{ SEER historic stage } \\
\hline Localized & 1 & & 1 & \\
\hline Regional & $1.168(0.878-1.553)$ & 0.287 & $1.878(1.144-3.082)$ & 0.013 \\
\hline Distant & $2.164(1.521-3.079)$ & $<0.001$ & $3.594(1.251-10.326)$ & 0.018 \\
\hline \multicolumn{5}{|l|}{ AJCC stage } \\
\hline I & 1 & & 1 & \\
\hline II & $0.653(0.361-1.182)$ & 0.159 & $1.874(0.730-4.809)$ & 0.191 \\
\hline III & $0.969(0.695-1.350)$ & 0.851 & $0.751(0.390-1.448)$ & 0.393 \\
\hline
\end{tabular}




\begin{tabular}{|c|c|c|c|c|}
\hline IV & $2.020(1.401-2.914)$ & $<0.001$ & $0.723(0.248-2.106)$ & 0.552 \\
\hline \multicolumn{5}{|l|}{ Stage $\mathbf{T}$} \\
\hline $\mathrm{T} 1$ & 1 & & 1 & \\
\hline $\mathrm{T} 2$ & $0.646(0.418-0.998)$ & 0.049 & $0.409(0.199-0.837)$ & 0.014 \\
\hline T3 & $0.847(0.579-1.237)$ & 0.390 & $0.783(0.466-1.316)$ & 0.356 \\
\hline T4 & $1.124(0.767-1.647)$ & 0.548 & $0.839(0.486-1.451)$ & 0.530 \\
\hline \multicolumn{5}{|l|}{ Stage N } \\
\hline No & 1 & & 1 & \\
\hline N1 & $1.301(0.957-1.768)$ & 0.093 & $1.468(1.008-2.139)$ & 0.046 \\
\hline \multicolumn{5}{|c|}{$\begin{array}{l}\text { Local treatment of } \\
\text { the primary tumor }\end{array}$} \\
\hline None & 1 & & 1 & \\
\hline Surgery & $0.393(0.246-0.630)$ & $<0.001$ & $0.555(0.316-0.977)$ & 0.041 \\
\hline \multicolumn{5}{|c|}{ Alpha fetoprotein } \\
\hline Elevated & 1 & & 1 & \\
\hline Normal & $1.015(0.622-1.655)$ & 0.953 & $1.077(0.643-1.805)$ & 0.778 \\
\hline \multicolumn{5}{|c|}{ Fibrosis score } \\
\hline $0-4$ & 1 & & 1 & \\
\hline $5-6$ & $1.419(0.320-6.299)$ & 0.645 & $0.682(0.141-3.302)$ & 0.635 \\
\hline
\end{tabular}

CI: confidence interval. 